\title{
The occurrence of malignancies in patients with rheumatoid arthritis treated with cyclophosphamide: a controlled retrospective follow-up
}

\author{
J. A. M. B ALTUS,${ }^{1} \mathrm{~J}$. W. BOERSMA,$^{2}$ A. P. HARTMAN,${ }^{1}$ A N D \\ J. P. VANDENBROUCKE ${ }^{2}$
}

From the ${ }^{1}$ Department of Rheumatology, Arnhem Municipal Hospital, and the ${ }^{2}$ Department of Epidemiology, Erasmus University, Rotterdam, The Netherlands

SUMMARY In a retrospective follow-up we compared the incidence of malignancies in patients with rheumatoid arthritis treated with cyclophosphamide with that in another group of patients with rheumatoid arthritis and also with the incidence of malignancies in the general population. Among 81 patients treated with cyclophosphamide in the past decade 15 malignancies occurred. This was $4 \cdot 1$ times the expected number obtained from a closely matched control group of patients with rheumatoid arthritis not treated with cytotoxic drugs (95\% confidence interval 1.5 to 19.0), and 3.7 times the expected number calculated from general population rates $(95 \%$ confidence interval $2 \cdot 1$ to $5 \cdot 9$ ). The increase in haematological and lymphoreticular malignancies was specially notable. The data also indicate that the development of malignancies after the start of cyclophosphamide therapy necessitates a certain induction time and that it is to some extent dose-dependent.

Following the publications by Fosdick et al. ${ }^{12}$ we started to treat rheumatoid arthritis (RA) patients with cyclophosphamide (CP) in the Arnhem Municipal Hospital in 1969. As elsewhere ${ }^{1-12}$ our clinical results were encouraging.

In the 1970 s, however, a disquieting number of case reports and restrospective follow-up studies indicated an increased occurrence of neoplasms, particularly of the haematological and lymphoreticular systems, due to cytotoxic therapy. This complication was first reported in transplant patients ${ }^{13-15}$ and later in various diseases, among them RA. ${ }^{816-26} \mathrm{We}$ decided to undertake this retrospective controlled study to get a better insight in the real occurrence of the malignancies and, in particular, the haematological and lymphoreticular malignancies. We had in fact been struck by a succession of this type of malignancies not only in patients treated with $\mathrm{CP}$ but also in patients who had never been treated with cytotoxic drugs. Moreover, both an increase and a decrease of malignancies have been reported in RA patients. ${ }^{27-37}$

The aim of this study was to compare the incidence of malignancies in our RA patients treated with $\mathrm{CP}$ with that in a comparable RA control group. In addi-

Accepted for publication 22 June 1982.

Correspondence to Dr J. W. Boersma, Department of Rheumatology, Arnhem Municipal Hospital, Wagnerlaan 55, 6815 AD Arnhem, The Netherlands. tion we compared this incidence with the cancer rates of the general population.

\section{Patients and methods}

The cyclophosphamide group consisted of 81 RA patients. Twenty-eight of them were in a small prospective follow-up study that one of us had started in $1971 .^{38}$ The other 53 were found by a systematic search through the inpatients records of the Arnhem Municipal Hospital over the period 1969-77. The reason for admission to hospital was either the start of $\mathrm{CP}$ therapy or evaluation for joint surgery in patients already being treated with the drug. For the latter patients the follow-up started at the date of beginning of the $\mathrm{CP}$ therapy. The dosage schedule consisted of a 2-week initial dose of $25 \mathrm{mg} /$ day, subsequently increased every 4 weeks by $25 \mathrm{mg} /$ day to a possible maximum of $150 \mathrm{mg} /$ day.

The 81 RA patients of the control group were selected from our in-patients records as patients who had never been treated with cytotoxic drugs, were of the same sex and 5-year age category, and had been admitted to hospital within one calendar year of their CP pair. The reasons for hospitalisation were the same as in the CP group: either the start of a new drug therapy (gold salts) or evaluation for joint surgery.

The common closing date of the follow-up was 1 July 1980. Survival status at that time and eventual 
cause of death were ascertained in all patients. If not enough information was available in our hospital records, we contacted the patient's general practitioner or requested pathological records from other hospitals.

In the analysis person-years of observation were counted per 5-year age categories in both sexes and in both groups. This allowed us to calculate age and sex specific incidence rates. By this method we could also calculate the number of malignancies that would have been expected in the $\mathrm{CP}$ group if the malignancy rates had been similar to those in the control group. Likewise we could calculate the number of malignancies expected in the CP group on the assumption that the age and sex specific rates for the general population of the Netherlands would have operated in that group. Disease rates for the general population of the Netherlands were obtained from publications of the Stichting Medische Registratie. By extrapolation from hospital discharge notes from a selection of hospitals this organisation was able to calculate age and sex specific 'first ever' admissions to hospital for all cancers in the Netherlands. ${ }^{39}$

Division of the number of malignancies observed in the $\mathrm{CP}$ group by the number expected yields the standardised morbidity ratio. ${ }^{40}$ To calculate the $95 \%$ confidence interval of the observed-to-expected $(\mathrm{O} / \mathrm{E})$ ratio when the expected number is calculated out of general population rates, one can make use of the large sample assumption that the observed number is a realisation of a Poisson variable, and that the expected number has a neglegible variance..$^{40}$ The exact $95 \%$ confidence limits of the observed number can then be found in standard tables of the confidence limits of Poisson variables ${ }^{41}$; the $95 \%$ confidence limits of the $\mathrm{O} / \mathrm{E}$ ratio are then obtained by the division of these confidence limits of the observed number by the expected number. In contrast, when the expected number is calculated from the malignancy rates in the RA control group, the assumption of a negligibly small variance cannot be made. In the calculation of the confidence limits of the $\mathrm{O} / \mathrm{E}$ ratio we now have to take into account both the variability of the observed and that of the expected number. This was accomplished by a logarithmic transformation of the $\mathrm{O} / \mathrm{E}$ ratio. Again assuming that the observed and the expected numbers are realisations of a Poisson variable, we can calculate the $95 \%$ confidence limits of $1 \mathrm{n}(\mathrm{O} / \mathrm{E})$ by the use of general approximate formulae for the variance of transformed random variables. ${ }^{40}$ The $95 \%$ confidence limits of the $\mathrm{O} / \mathrm{E}$ ratio itself are then obtained as the exponential of the confidence limits of $1 \mathrm{n}(\mathrm{O} / \mathrm{E})$. The main use of the confidence interval is to give the reader an impression of the statistical uncertainty of the observed-to-expected ratio. The confidence interval of the ratio calculated with the RA control group will inevitably be wider than the confidence interval of the ratio calculated with the general population rates.

We also plotted the occurrence of malignancies in each year of follow-up as a percentage of the number still under observation. This graphical display was intended to illustrate a time-occurrence relationship. Finally we calculated the total dose received by the persons developing malignancies and by the persons who did not develop a malignancy. To assess the statistical significance of the difference in dose and duration of therapy between the $\mathrm{CP}$ patients who developed a malignancy and those that did not we used the $t$ test for the difference between 2 means.

\section{Results}

The characteristics of the CP-treated patients with RA and of the matched RA control group are shown in Table 1. The duration of follow-up in the control group was somewhat longer owing to the longer survival of these patients.

An enumeration of the malignancies that occurred in the CP-treated patients with RA and in the matched RA control group is given in Table 2 .

The observed and the expected number of malignancies in the CP-treated patients with RA, the observed/expected ratio, and its confidence interval are given in Table 3 . The observed/expected ratios all differ significantly from unity at the $5 \%$ level.

The observed and expected number of haematolymphoreticular malignancies in CP-treated patients with RA, the observed/expected ratio, and its confidence interval are given in Table 4. In this table we contrast the observed number in the $\mathrm{CP}$ group with the expected number derived from the general population rates for the Netherlands. A calculation of the

Table 1 Characteristics of CP-treated RA patients and of the matched RA control group

\begin{tabular}{|c|c|c|}
\hline & $C P$ & Controls \\
\hline Number & 81 & 81 \\
\hline Males (number) & 26 & 26 \\
\hline Females (number) & 55 & 55 \\
\hline Age (mean and range) & $57 \cdot 8(32-86)$ & $57 \cdot 8(34-83)$ \\
\hline $\begin{array}{l}\text { Disease duration } \\
\text { (mean and range, years) }\end{array}$ & $12 \cdot 0(1-37)$ & $11 \cdot 4(0.5-39)$ \\
\hline $\begin{array}{l}\text { Duration of } C P \text { therapy } \\
\text { (mean and range, years) }\end{array}$ & $3 \cdot 8(0 \cdot 2-8 \cdot 1)$ & 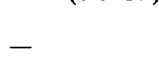 \\
\hline $\begin{array}{l}\text { Duration of follow-up } \\
\text { (mean and range, years) }\end{array}$ & $6 \cdot 5(1 \cdot 2-11 \cdot 0)$ & $7 \cdot 1(1-10 \cdot 5)$ \\
\hline $\begin{array}{l}\text { Previous steroid the rapy } \\
\text { (number) }\end{array}$ & 19 & 12 \\
\hline Joint surgery (number) & 4 & 16 \\
\hline Sero-positivity (number) & 69 & 52 \\
\hline
\end{tabular}


Table 2 Enumeration of malignancies occurring in 81 CP-treated RA patients and in matched control group

\begin{tabular}{|c|c|c|c|c|c|c|c|}
\hline \multicolumn{4}{|c|}{ Cyclophosphamide group } & \multicolumn{4}{|c|}{ Control group } \\
\hline No. & $M / F$ & Diagnosis (localisation) & Age & No. & $M / F$ & Diagnosis (localisation) & Age \\
\hline 1 & $\mathbf{M}$ & Grawitz tumour & 48 & 1 & $\mathbf{M}$ & Squamous cell ca lung & 74 \\
\hline 2 & $\mathbf{M}$ & Squamous cell ca lung & 55 & 2 & $\mathbf{F}$ & Cervix carcinoma & 48 \\
\hline 3 & $\mathbf{M}$ & Basal cell ca skin & 61 & 3 & $\mathbf{F}$ & Tonsil carcinoma & 51 \\
\hline 4 & $\mathbf{M}$ & Basal cell ca skin & 59 & 4 & $\mathbf{F}$ & Basal cell carcinoma skin & 74 \\
\hline 6 & $\mathbf{M}$ & Squamous cell ca lung & 75 & & & & \\
\hline 7 & $\mathbf{M}$ & Malignant reticulosis & 81 & & & & \\
\hline 8 & $\mathbf{M}$ & Oatcell ca lung & 83 & & & & \\
\hline 9 & $\mathbf{F}$ & Non-Hodgkin lymphoma & 51 & & & & \\
\hline 10 & $\mathbf{F}$ & Carcinoma uteri & 54 & & & & \\
\hline 11 & $\mathbf{F}$ & Carcinoma pancreas & 59 & & & & \\
\hline 12 & $\mathbf{F}$ & Non-Hodgkin lymphoma & 66 & & & & \\
\hline 15 & $\mathbf{F}$ & Myelofibrosis & 67 & & & & \\
\hline
\end{tabular}

Table 3 Observed and expected number of malignancies in $81 C P$-treated $R A$ patients

\begin{tabular}{lllll}
\hline & Observed & $\begin{array}{c}\text { Expected O/E } \\
\text { ratio }\end{array}$ & $\begin{array}{l}95 \% \text { CI of } \\
\text { O/E ratio }\end{array}$ \\
\hline $\begin{array}{l}\text { Expected number } \\
\text { calculated with RA } \\
\text { controls }\end{array}$ & 15 & 3.6 & $4 \cdot 1$ & $1 \cdot 3-13 \cdot 0^{*}$ \\
$\begin{array}{l}\text { Expected number } \\
\text { calculated out of } \\
\text { general population }\end{array}$ & 15 & $4 \cdot 0$ & $3 \cdot 7$ & $2 \cdot 1-6 \cdot 2 \dagger$ \\
\hline $\begin{array}{l}\text { *Calculated via logarithmic transformation. } \\
\text { +Calculated under large sample assumption. } \\
\text { CI = confidence interval. }\end{array}$ & & & \\
\end{tabular}

Table 4 Observed and expected number of malignancies of the haematological and lymphoreticular systems in 81 $C P$-treated $R A$ patients

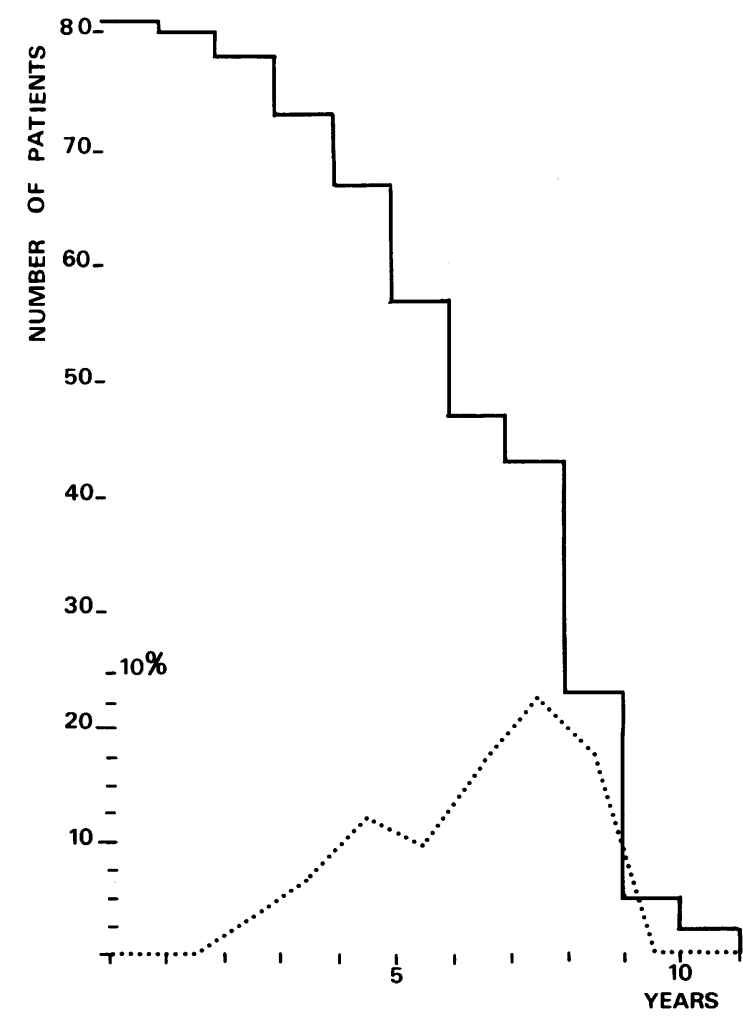

expected number of the haematolymphoreticular malignancies based upon the RA control group had no meaning because no such malignancies occurred in this control group.

The observed number of visceral and skin tumours in the CP-treated RA groups was 2 to 3 times the expected number, both in comparison with the RA control group and with the general population rates for the Netherlands. The visceral tumours were

Fig. 1 Percentage occurrence of malignancies in the years of follow-up after the start of CP treatment.

Number of patients observed. . . . . Percentage occurrence of malignancies. 
Table $5 C P$ dose received and duration of $C P$ therapy in 81 RA patients

\begin{tabular}{llll}
\hline & $\begin{array}{l}15 \text { patients } \\
\text { with } \\
\text { malignancy }\end{array}$ & $\begin{array}{l}66 \text { patients } \\
\text { without } \\
\text { malignancy }\end{array}$ & \\
\hline $\begin{array}{l}\text { Mean dose }(\mathrm{g}) \text { and } \\
\text { range }\end{array}$ & $82(23-176)$ & $61(5-171)$ & $\mathrm{p}=0.054^{*}$ \\
$\begin{array}{l}\text { Mean duration of } \\
\text { therapy }(\mathrm{yr}) \text { and } \\
\text { range }\end{array}$ & $4.5(1.9-8.1)$ & $3.6(0.2-8 \cdot 1)$ & $\mathrm{p}=0.229+$ \\
\hline
\end{tabular}

$* \mathrm{t}=1.96, \mathrm{DF}=79$.

$t_{t}=1 \cdot 21, D F=79$.

dominated by the occurrence of 4 lung cancers in the CP-treated males. Numbers, however, became very small on splitting up further for type of malignancy, age, or sex, so that confidence intervals were very wide. Further conclusions based on subgroups of the material were deemed to be unwarranted.

The occurrence of malignancies in the years of follow-up from the start of CP treatment is plotted in Fig. 1. The number of malignancies is expressed as a percentage of the number of patients observed in each follow-up year group.

The $\mathrm{CP}$ dose received and duration of $\mathrm{CP}$ therapy are given in Table 5. Although the ranges are wide, there is a clear gradient between the patients who developed a malignancy and those who did not.

\section{Discussion}

Our findings indicate an approximately 4-fold increase in the overall incidence of malignancies among RA patients treated with CP. This 4-fold increase is found in comparison with RA patients that had never been treated with cytotoxic drugs as well as in comparison with the general population. Most impressive was the increase in the haematological and lymphoreticular malignancies. The latter are estimated to be increased about 15 -fold in comparison with the general population.

When a control group is chosen to estimate the expected number of malignancies, it is obvious that the most valid control group would consist of RA patients of similar age and sex and with a disease course of similar severity. We have tried to achieve this by taking into the control group only RA patients who had been treated as inpatients, and by matching them with the CP group by age, sex, and date of admission to hospital. Thus the RA control patients were all patients with severe disease who required hospitalisation, either for the start of a new drug therapy or for evaluation of joint surgery. We have tried to assess the comparability of the 2 groups by the information given in Table 1 . Whether one can ever guarantee complete comparability when the selection is not randomised is a matter of debate. In principle one could argue that patients who have once been selected for CP treatment will never be exactly like another group of patients who have not (yet) been selected for that form of treatment, whatever some parameters for disease activity show. In consequence one could maintain that it is the disease course of this selected group of CP-treated patients, rather than the therapy they receive, which is responsible for their higher malignancy rates. The likelihood of the latter explanation namely, that a presumably small - difference in disease course could cause a many-fold increase in tumour occurrence, is questionable. However, it may be noted that one of the patients in the CP-treated group who developed a basal cell skin carcinoma suffered also from psoriatic erythrodermia, and that another was described by the attending dermatologist as a victim of a 'tropical skin'. As for the higher lung cancer rates in the CPtreated group, we lack comparative information about the smoking histories of the 2 groups.

The close matching requirements that we had imposed on our RA control group made it impossible to find more than one RA control for each CP patient. The resulting problem, the relative smallness of the control group, is well demonstrated by the fact that no haematological or lymphoreticular malignancies developed in control patients, so that the observed-to-expected ratio cannot be estimated. Therefore we calculated a comparison with the general population. We realised that such a comparison of CP-treated RA patients with the general population might have less validity, since both higher and lower incidences of malignancies have previously been reported in comparisons between RA patients and general populations. ${ }^{42-47}$ Nevertheless, general population rates are the most stable that are available owing to the large numbers upon which they are based. The closeness of the results of the comparison between the general population and the RA control group was reassuring.

To corroborate further the causal nature of the association between the increased occurrence of malignancies and CP therapy we used 2 other descriptions of the CP-treated patients. First, the plot of the percentage occurrence of malignancies in each year of follow-up (Fig. 1) shows a rise up to a 7 to $9 \%$ annual tumour occurrence in 3 consecutive years. In the general population one would expect a yearly occurrence that would be only about $0.5 \%$. The descending part of the peak in Fig. 1 concerns estimates based on small numbers only, which entails great follow-up statistical uncertainty. Nevertheless the 3 very high occurrences after 7,8 , and 9 years of 
follow-up fit the idea of a tumour induction that shows itself after a certain time lag, which corresponds to general concepts of carcinogenesis. A contrary finding, an even spread of the tumour occurrence over time, would have rendered the causality of the association less likely. Secondly, the total CP dose received and the duration of therapy were higher in those patients who developed a malignancy. The difference was of borderline statistical significance only for the dosage.

Our investigation was started from the hypothesis that much of the alarm about cytotoxic therapy was due to inadequate control groups. Our findings concerning malignancies associated with $\mathrm{CP}$ confirm most of the recent reports about alkylating agents. ${ }^{48-52}$ By contrast, some workers ${ }^{53-55}$ did not report such an association in their studies. Nevertheless, at present our policy is to reserve $\mathrm{CP}$, however beneficial, for the fully informed patient in whom all other therapy failed and who clearly announces that a life with pain and disablement is not worthwhile living.

\section{References}

1 Fosdick W M, Parsons J L, Hill D F. Long-term cyclophosphamide therapy in rheumatoid arthritis. Arthritis Rheum 1968; 11: $151-61$.

2 Fosdick W M, Parsons J L, Hill D F. Long-term cyclophosphamide therapy in rheumatoid arthritis: a progress report, six years' experience. Arthritis Rheum 1969; 12: 663.

3 Cooperating Clinics Committee of the American Rheumatism Association. A controlled trial of cyclophosphamide in rhe umatoid arthritis. $N$ Engl J Med 1970; 283: 883-9.

4 Cooperating Clinics Committee of the American Rheumatism Association. A controlled trial of high and low doses of cyclophosphamide. Arthritis Rheum 1972; 15: 434-5.

5 Williams H J, Reading J C, Ward J R, O'Brien W M. Comparison of high and low dose cyclophosphamide therapy in rhe umatoid arthritis. Arthritis Rheum 1980; 23: 521-7.

6 Steinberg A D, Plotz P H, Wolff S M, Wong G, Agus S G, Decker J L. Cytotoxic drugs in treatment of nonmalignant diseases (NIH conference). Ann Intern Med 1972; 76: 619-42.

7 Currey H L F, Harris J, Mason R M, et al. Comparison of azathioprine, cyclophosphamide, and gold in treatment of rheumatoid arthritis. Br Med J 1974; iii: 763-6.

8 Townes A S, Sowa J M, Shulman L E. Controlled trial of cyclophosphamide in rheumatoid arthritis. Arthritis Rheum 1976; 19: 563-73.

9 Pirofsky B, Bardana E J Jr. Immunosuppressive therapy in rheumatic disease. Med Clin North Am 1977; 61: 419-37.

10 Stojanovic I, Budimir M, Nikolic J, Maksimovic B, Berovic Z. Duration of improvement after good response to cyclophosphamide treatment. Scand J Rheumatol 1978; 7: 1-2.

11 Scott D G I, Allen C, Papadimitriou G, Bacon P A. Effect of immunosuppression in rheumatoid synovitis and vasculitis. Ann Rheum Dis 1980; 39: 196.

12 Kent Ph. The slow miracle. Br Med J 1981; 282: 2029-30.

13 Penn I, Starzl Th E. Immunosuppression and cancer. Transplant Proc 1973; 5: 943-7.

14 Sieber S M, Adamson R H. Toxicity of antineoplastic agents. Adv Cancer Res 1975; 22: 104-55.

15 Penn I. Second malignant neoplasms associated with immunosuppressive medication. Cancer 1976; 37: 1024-32.
16 Pollock B H, Barr J H, Stolzer B J. Neoplasia and cyclophosphamide. Arthritis Rheum 1973; 16: 524-5.

17 Parsons J L, Strong J S, Fosdick W M. The causes of death in patients with rheumatoid arthritis treated with cytotoxic agents. J Rheumatol 1974; 1: (suppl): 75.

18 Tannenbaum $\mathrm{H}$, Schur $\mathrm{P}$ H. Development of reticulumcell sarcoma during cyclophosphamide therapy. Arthritis Rheum 1974; 17: 15-8.

19 Wall R L, Clausen K P. Carcinoma of the bladder in patients receiving cyclophosphamide. $N$ Engl J Med 1975; 293: 271-3.

20 Love R R, Sowa J M. Myelomonocytic leukaemia following cyclophosphamide therapy of rheumatoid disease. Ann Rheum Dis 1975; 34: 534-5.

21 Seidenfeld A M, Smyth H A, Ogryzlo A M, Urowitz M B, Dotten D A. Acute leukaemia in rheumatoid arthritis treated with cytotoxic agents. J Rheumatol 1976; 3: 295-304.

22 Kyle R R, Pierre R V, Bayrd E D. Therapy linked leukaemia. Lancet 1977 ; i: $519-20$.

23 Puri H C, Campbell R A. Cyclophosphamide and malignancy. Lancet 1977; i: 1306.

24 Davis J D, Muss H B, Turner R A. Cytotoxic agents in the treatment of rheumatoid arthritis. South Med J 1978;71: 58-64.

25 Penn I. Malignancies associated with immunosuppressive or cytotoxic therapy. Surgery 1978; 84: 492-502.

26 Auclerc G, Jaquillat C, Auclerc M F, Weil M, Bernard J. Posttherapeutic acute leukaemia. Cancer 1979; 44: 2017-25.

27 Calabro J J. Cancer and arthritis. Arthritis Rheum 1967; 10: 553-67.

28 Miller D G. The association of immune disease and malignant lymphoma. Ann Intern Med 1967; 66: 507-21.

29 Oleinick A. Leukaemia or lymphoma occurring subsequent to an autoimmune disease. Blood 1967; 29: 144-53.

30 Goldenberg G J, Paraskevas F, Israels L G. The association of rheumatoid arthritis with plasmacell and lymphocytic neoplasms. Arthritis Rheum 1969; 12: 569-79.

31 Owen D S, Waller M, Toone E C Jr. Rheumatoid arthritis and malignancy. Med Coll Virginia $Q$ 1969; 6: 8-10.

32 Anderson L G, Talal N. The spectrum of benign to malignant lymphoproliferation in Sjögren's syndrome. Clin Exp Immunol 1971; 9: 199-221.

33 Banks P M, Witrak G A, Conn D L. Lymphoid neoplasia following connective tissue disease. Mayo Clin Proc 1979; 54: 104-8.

34 Gardner D L. The pathology of rheumatoid arthritis. London: Arnold, 1972: 183-7.

35 Lewis R B, Castor C W, Knisley R E, Bole G G. Frequency of neoplasia in systemic lupus erythematosus and rheumatoid arthritis. Arthritis Rheum 1976; 19: 1256-60.

36 Mutru O, Koota K, Isomäki H. Causes of death in autopsied RA patients. Scand J Rheumatol 1976; 5: 239-40.

37 Rainer F, Klein G, Schmid P, Härringer M. Untersuchungen über Art und Häufigkeit der Todesursachen bei chronischer Polyarthritis. Z Rheumatol 1978; 37: 335-41.

38 Hartman A P, Hoffman-Knottenbelt N. Behandeling met cyclophosphamide bij RA; een gecontroleerd onderzoek bij 33 patiënten. Ned Tijdschr Geneeskd 1975; 119: 1019.

39 Centraal Bureau voor de Statistiek, Stichting Medische Registratie. Kanker Morbiditeit en Mortaliteit. 's-Gravenhage: Staatsuitgeverij, ' 1979.

40 Armitage P. Statistical methods in medical research. Oxford: Blackwell, 1971: 388-91.

41 Pearson E S, Hartley H O, eds. Biometrika tables for statisticians. Cambridge: Cambridge University Press, 1970; 1: 227.

42 Cobb S, Anderson F, Bauer W. Length of life and cause of death in rheumatoid arthritis. $N$ Engl J Med 1953; 249: 553-6.

43 Duthie J R, Brown P E, Truelove L H, Baragar F D, Lawrie A J. Course and prognosis in rheumatoid arthritis-a further report. Ann Rheum Dis 1964; 23: 193-204.

44 Uddin J, Kraus A S, Kelly H G. Survivorship and death in rheumatoid arthritis. Arthritis Rheum 1970; 13: 125-30.

45 Isomäki H A, Mutru O, Koota K. Death rates and causes of 
death in patients with rheumatoid arthritis. Scand $J$ Rheumatol 1975; 4: 205-8.

46 Monson R R, Hall A P. Mortality among arthritics.J Chron Dis 1976; 29: 459-67.

47 Isomäki H A, Hakulinen T, Joutsenlathi U. Excess risk of lymphomas, leukaemia and myeloma in patients with rheumatoid arthritis. J Chron Dis 1978; 31: 691-6.

48 Renier J C, Bregeon, C, Bonnette C, et al. Le devenir des sujets atteints de polyarthrite rhumatoide et traités par les immunodépresseurs entre 1965 et 1973 inclus. Rev Rhum Mal Osteoartic 1978; 45: 453-61.

49 Kahn M F, Arlet J, Bloch-Michel H, Caroit M, Chaouat Y, Renier $\mathrm{J}$ C. Leucémies aiguës après traitement par agents cytotoxiques en rhumatologie (19 observations chez 2006 patients). Nouv Presse Med 1979; 8: 1393-7.

50 Prieur A M, Balafrei M, Griscelli C, Mozziconacci P. Résultats et risques à long terme des traitments immunosuppresseurs dans l'arthrite chronique juvénile (à propos de $\mathbf{4 0}$ observations). Rev Rhum Mal Osteoartic 1979; 46: 85-90.

51 Reimer R R, Hoover R, Fraumeni J F Jr, et al. Acute leukaemia after alkylating-agent therapy of ovarian cancer. $N$ Engl J Med 1977; 297: 177-81.

52 Kinlen L J, Sheil A G R, Peto J, Doll R. Colloborative United Kingdom-Australian study of cancer in patients treated with immunosuppressive drugs. Br Med J 1979; ii: 1461-6.

53 Farber S J, Sheon R P, Kirsner A B, Finkel R I. Incidence of malignant disease in patients receiving cytotoxic therapy for rheumatoid arthritis. Arthritis Rheum 1979; 22: 608.

54 Kirsner A B, Farber S J, Sheon R P, Finkel R I. Incidence of malignant disease in patients receiving cytotoxic therapy for rheumatoid arthritis. Arthritis Rheum 1981; 41 (suppl): 32-3.

55 Boyle D J, Day J F, Kassan S S, Thomas M R, Robinson W A, Steigerwald J C. Incidence of malignancy 10 years following cyclophosphamide use for rheumatoid arthritis. Arthritis Rheum 1981; 24 (suppl): 71 